\title{
O Teatro de Sami Feder no Holocausto: Um espaço de Resistência
}

\author{
Leslie Evelyn Ruth Marko
}

Instituição e tipo de vínculo: Faculdade de Filosofia, Letras e Ciências Humanas (FFLCH) da Universidade de São Paulo (USP).

Doutoranda

Projeto em andamento

Área de Estudo: Teatro, História e Holocausto.

Orientadora: Profa Dra .Maria Luiza Tucci Carneiro

Atuação profissional: Docente na Escola Superior de Propaganda e Marketing (ESPM), Pesquisadora e coordenadora de oficinas de teatro do ARQSHOAH, arquivo virtual de Holocausto e antissemitismo e do Laboratório de Estudos de Etnografia, Racismo e Discriminação (LEER/Historia/USP)

\section{Resumo}

Esta pesquisa pretende resgatar e analisar a atuação estética, social e histórica do diretor de teatro, judeu-polonês, Sami Feder (1909-2000) no contexto de grupos teatrais de resistência anti-hitlerista, compostos por artistas e prisioneiros judeus, em guetos, campos de concentração, de trabalho e extermínio durante a dominação nazifascista principalmente na Alemanha e no Leste Europeu.

Será realizado o levantamento de materiais sobre o tema: bibliografia, arquivos e acervos de bibliotecas nacionais e internacionais, reportagens, documentos, álbuns de fotografia, diários, textos teatrais, entrevistas com sobreviventes, dramaturgos e pesquisadores acadêmicos. Será estabelecido, também, um diálogo com autores que analisam o período tais como Bertolt Brecht, Theodor Adorno, Rebecca Rovit, Robert Skloot, Viktor Frankel,Walter Benjamin Zygmunt Bauman, Stephen Wilner entre outros.

Palavras-chave: desumanização, KZ Theater, nazifascismo, Sami Feder, Teatro Judaico.

Title: Sami Feder`s Theater through the Holocaust: A space for Resistance

\section{Abstract}

This research intends to rescue and analyze the performance aesthetics, social and historical of the Jewish - polish theater director Sami Feder (1909-2000) in the context of resistance and anti-Hitler theater groups, composed by Jewish artists and prisoners in ghettos, concentration, work and extermination camps during the Nazifascist domination mainly in Germany and Eastern Europe.

Will be conducted the survey of material on the topic:: literature, archives and library international and national collections, reports, documents, photo albums, diaries, plays, interviews with survivors, play-writers and academic researchers.

There will be a dialogue with authors who analyze the period such as Bertolt Brecht, Theodor Adorno, Rebecca Rovit, Robert Skloot, Viktor Frankel, Walter Benjamin, Zygmunt Bauman, Stephen Wilner and others. Keywords: dehumanization, Jewish theater, KZ Theater, Nazi fascism, Sami Feder. 
Título: El Teatro de Sami Feder en el Holocausto: Un espacio de Resistencia

\section{Resumen}

Esta investigación tiene como objetivo recuperar y analizar la actuación estética, social e histórica del director de Teatro judío polaco, Sami Feder (1909-2000) en el contexto de la resistencia contra Hitler, integrada por artistas y prisioneros judíos en guetos, campos de concentración, trabajo y exterminio durante la dominación nazi fascista principalmente en Alemania y Europa del Este.

Se llevará a cabo el levantamiento de materiales sobre el tema: bibliografía, archivos y colecciones de bibliotecas nacionales e internacionales, informes, documentos, álbum de fotos, periódicos, textos teatrales, entrevistas con sobrevivientes, dramaturgos e investigadores académicos. Habrá un diálogo con los autores que analizan el periodo Bertolt Brecht, Theodor Adorno, Rebecca Rovit, Robert Skloot, Viktor Frankel, Walter Benjamin Zygmunt Bauman, Stephen Wilner entre otros.

Palabras clave: deshumanización, KZ Theater, nazi fascismo, Sami Feder, Teatro Judío

\section{INTRODUÇÃO}

\section{"A vontade de criar era a vontade de viver" Victor Ulmann, artista assassinado em Auschwitz}

Este artigo é parte da minha pesquisa de doutorado em andamento, cujo objetivo é a investigação do movimento de resistência desenvolvido por artistas, atores, diretores, autores e espectadores durante o período em que o nazi-fascismo dominou grande parte da Europa (1939-45) e imediatamente, após a liberação dos campos de concentração, especialmente o de Bergen Belsen (1945-1947). Pretendo, neste estudo, analisar a atuação de Sami Feder, entre outros artistas, que procuraram exercer acolhimento coletivo, ético e de cidadania, por meio do Teatro. Considero que Sami Feder exercia uma intervenção na realidade adversa, injusta e violenta nos tempos sombrios daquele período, por meio de teatro. Ações intervencionistas como esta se espalharam pela Europa ocupada como uma reação a processos de desumanização instalados pelo Estado nacional-socialista e os governos colaboracionistas. Ações armadas, artísticas, ideológicas e espirituais ocorreram durante o Holocausto como reação contra a doutrinação e a opressão alemã no período.

Paradoxos e ambiguidades acompanharam a criação teatral durante o nazismo. Representações teatrais autorizadas e/ou clandestinas aconteciam em regiões e em fases diferentes e de formas diversas. De fato, para os atores e espectadores, protagonistas do fenômeno, quando proibido, estava relacionado com os riscos e a coragem de estar "lá". 
Isso também significou que para se refugiar durante algumas horas dentro da dimensão da ficção e longe da cruel realidade, artistas e público eram capazes de escalar montes de lixo e sujeira acumulados nas ruas do gueto e dos campos para chegar até os palcos de teatro clandestino. O objetivo era "transcender" o horror da destruição para alcançar palcos talvez "mágicos" onde cada um poderia "escapar" e compartilhar preciosos sentimentos de humanidade. É interessante observar que palcos improvisados e subterrâneos eram criados em becos, pequenos apartamentos, corredores estreitos do gueto, ou mesmo, em cantos escuros dos barracões dos campos. Neles, atores e público criaram uma "outra" realidade ao esconder-se para dividir suas valiosas histórias, protegidos por velhos pedaços de cobertores que cobriam as janelas.

Assim, o Teatro era uma forma de manter algum nível de dignidade motivando os espectadores a continuar vivendo e trazendo alguma esperança, tão necessária, para aquele público fragilizado. $\mathrm{Na}$ clandestinidade, encenações curtas e rápidas puderam transmitir informações ou notícias urgentes nos guetos. Podiam, também, ser entretenimento como uma distração possível. Além disso, o teatro ídiche pode ajudar a manter vivo o Judaísmo, pois cenas curtas sobre tradição e feriados judaicos eram apresentadas, principalmente para o público infantil, proibido de frequentar escolas e instituições judaicas em geral. O teatro podia, ainda, representar situações realistas vinculadas ao dia a dia do confinamento e discriminação, fato que favorecia a identificação coletiva, o exercício de reflexão sobre as próprias condições de vida e um canal que permitia dar vazão às próprias emoções.

Outro aspecto importante é que a prática do teatro subterrâneo podia se constituir num meio de burla e crítica em relação aos nazistas. Também, apesar da tristeza e dor, o humor, que não é uma forma rara de representação, desempenhou um papel importante durante a guerra: dramaturgos do teatro idiche como Scholem Aleichem e Moishe Nadir, foram encenados por atores interessados em manter viva a alma e o humor judaico. Mesmo rindo de si mesmos e, talvez, por isso mesmo era possível manter a sensação de estarem vivos. 


\section{DESENVOLVIMENTO}

O Holocausto nasceu e foi executado na nossa sociedade moderna e racional, em nosso alto estágio de civilização e no auge do desenvolvimento cultural humano, e por essa razão é um problema dessa sociedade, dessa civilização e cultura.

(BAUMAN, 1998)

Após realizar uma pesquisa exploratória, buscando expressões de teatro judaico contra a desumanização nesse período, entrei em contato com alguns autores, como os norte-americanos Robert Skloot e Rebecca Rovit. Descobri também livros, arquivos e materiais sobre diferentes educadores, atores e diretores conhecidos na época, como Janusz Korzcak, Max Ehlich, Charlotte Kurt Delbo, Chean Nava, Fantlová Zdenka. Interessei-me, também, pelo estudo de uma companhia de teatro representativa na época, o Grupo de Teatro de Vilna, que teve forte compromisso artístico e ideológico contra o nazismo, paralelamente ao combativo movimento partizano que lutava nos bosques de Ponar, nos arredores de Vilna.

Entretanto, descobri que o dramaturgo israelense contemporâneo, Joshua Sobol tinha feito uma profunda pesquisa sobre o Grupo de Vilna e havia escrito uma peça impactante chamada Ghetto, em 1984 - parte de uma trilogia sobre o Holocausto. A peça vem sendo encenada no mundo todo nos últimos 25 anos. Sobol escreveu também o roteiro para o filme com o mesmo título da peça teatral que foi dirigida pelo cineasta lituano Juzenas Andrius, em 2006. Encontrei também várias dissertações, artigos e teses em torno da obra de Sobol.

Fiel à ideia desta tese que era, desde o início, encontrar e pesquisar um artista ou grupo de teatro, cuja prática teatral apresentasse uma estética capaz de expressar uma força de resistência ideológica, espiritual e de denúncia durante o Holocausto, decidi continuar minha investigação na busca de artistas pouco conhecidos, mas que pudessem trazer uma nova contribuição ao campo de pesquisa sobre o Teatro no Holocausto.

Um momento importante, neste percurso, aconteceu quando Moti Sandak, coordenador de um site de teatro judaico internacional (www.jewish-theater.com) apresentou-me a uma professora russa residente em Israel, Dra. Zlata Zaretsky, Ph.D. da Universidade de Moscou, autora de The Phenomenon of Theater Israeli, A view of 
history and the present time, que entrevistou Sami Feder e sobre quem escreveu um artigo, diretor de teatro polonês judeu que teria atuado ativamente, durante o genocídio nazista. Recebi gentilmente da Profa Zaretsky parte do arquivo pessoal de Feder contendo inclusive suas notas pessoais, escritas em Ídiche e ainda não publicadas, com o título de Diário do Teatro de Campo de Concentração de Bergen Belsen. O arquivo foi entregue a ela por Dora Feder, esposa de Sami, após a morte do artista. Meu interesse e curiosidade aumentaram ainda mais, quando li o seu diário, do qual existe, inclusive, uma cópia, dada pelo próprio Feder ao Museu do Holocausto, Yad Vashem em Jerusalém.

A leitura do diário de Feder e o artigo de Zaretsky confirmaram a importância de aprofundar uma pesquisa sobre este artista, pois, além de criar uma estética surpreendente e singular ancorada numa visão ideológica antinazista que implicava numa ação interventiva na realidade dos prisioneiros judeus dentro dos campos de concentração, ele conseguiu manter-se vivo durante e, após o Holocausto, ajudando muita gente a se manter viva também.

Sami Feder nasceu na Polônia e passou a infância e adolescência em Frankfurt e Berlin. Estudou teatro na Alemanha e fez parte de Companhias de Teatro Ídiche tanto lá como na Polônia. $\mathrm{O}$ ator, escritor, diretor e cenógrafo passou por 12 diferentes campos de concentração, trabalho e extermínio, especialmente no campo alemão de Bergen Belsen, onde criou e dirigiu o Teatro KZ. A Companhia foi oficialmente reconhecida após a libertação, em 1945 e continuou seu trabalho, mesmo com dificuldades, até 1947. Durante a tournée pela Bélgica, França e Inglaterra, o Teatro KZ recriou encenações representadas dentro dos campos em uma versão mais longa e completa e com maiores recursos de produção. A Companhia aproveitou a oportunidade para denunciar a situação humana terrível que ainda se vivia em Bergen Belsen, mesmo após a sua libertação.

Após alguns meses de pesquisa, constatei que havia pouca informação, mesmo em arquivos e bibliotecas no Museu Yad Vashem e no Museu do Holocausto de Washington sobre Sami Feder. Além do interesse e curiosidade iniciais, parecia-me agora, essencial o estudo e a análise do trabalho valioso, politicamente engajado e antiHitleriano, tão pouco conhecido e divulgado de um artista de teatro da envergadura de Sami Feder.

Com a escolha do objeto de pesquisa e definição de objetivos do meu doutorado, encontrei também um caminho para me aproximar de uma questão que me intrigava: 
como compreender a sobrevivência de encenações em condições tão adversas e que possibilitavam manter viva uma referência comunitária? Por meio da obra de Sami Feder, encontrei um trabalho teatral que resgatava, por meio da memória oral coletiva, a preservação da cultura judaica e por meio de textos universais de antes da guerra (inclusive de autores da Literatura e do Teatro banidos pelo nazismo) parte da própria memória da civilização. Além disso, a escrita e encenação de uma nova dramaturgia por Feder, representando e elaborando situações da realidade traumática vivida nos guetos e campos de concentração, ajudava atores e espectadores a digeri-las. Isso significava mais uma ação de intervenção na realidade por meio do teatro.

\section{OBJETIVOS}

Nesta pesquisa, meu objetivo é conhecer, resgatar e dar visibilidade ao Teatro Judaico antinazista de Sami Feder no período de 1933 a 1947. Para isso, pretendo seguir seus passos ao longo de sua dura jornada, descrevendo suas produções, desafios, processos de criação, dificuldades e resultados. Pretendo também analisar a estética criada por Feder, já que por meio dela, o diretor polonês pôde exercer uma prática ética de acolhimento coletivo, preservação da identidade judaica e dignidade humana. Em artigos de jornais diferentes, pude encontrar referências a Feder em que ele é definido como um "terapeuta de grupo" dado que o vínculo que estabelecia com seu público promovia momentos de comoção, silêncio, gritos, pensamentos e sentimentos compartilhados que, como já dito, se constituíam em diferentes formas de elaboração da realidade traumática vivida por atores e espectadores. Assim, trata-se de uma contribuição significativa para a história do teatro judeu e acima de tudo, para a história da dignidade humana.

Estabelecer pontes entre o Teatro de Feder e situações contemporâneas de violência e discriminação extrema poderá ser inspirador para incrementar as práticas teatrais engajadas na atualidade.

Durante o desenvolvimento da presente pesquisa, pretendo, por meio de palestras, artigos, oficinas e futuramente encenações, contribuir na divulgação do Teatro de Resistência durante o Holocausto em geral e da pratica engajada de Sami Feder em particular. 


\section{METODOLOGIA}

Para pesquisar sobre o movimento teatral geral de resistência durante $o$ Holocausto e a obra de Sami Feder, especificamente, pretendo realizar um levantamento e analise de materiais significativos em arquivos pessoais e institucionais nacionais e internacionais, bibliotecas, artigos de jornais e entrevistas com sobreviventes e especialistas, fotos, livros, programas, textos de peças e diários pessoais raros.

Acredito que, ao desvendar dados sugeridos pelo diário pessoal de Feder, poderei encontrar instituições e pessoas (ou seus descendentes) mencionadas em suas notas que ofereçam novos aportes ao resgate de sua obra. Baseada nas informações de Feder, buscarei reconstruir seu percurso, desde o início: num primeiro momento, como estudante de teatro em Berlim, onde foi aluno de Erwin Piscator, precursor do teatro político e também colega de Bertolt Brecht. Num segundo momento, como ator e diretor do Teatro Ídiche em Frankfurt e Varsóvia. Num terceiro momento, como diretor e articulador de ações culturais, ideológicas e artísticas em diferentes campos de concentração, especialmente em Bergen Belsen.

Tentarei também, revelar aspectos da estética de Feder criada nos campos antes da libertação e, desconhecidos principalmente por causa da impossibilidade do registro de documentos históricos por meio de fotografias, filmes, programas impressos, partituras ou mesmo artigos dentro dos campos. Pretendo ainda, pesquisar o período de dois anos que o KZ Theater viajou pela Europa, para conhecer o repertório dos espetáculos e a reação política e artística das autoridades e comunidades judaicas nos países visitados. E também, investigar os últimos 40 anos de Feder vivendo em Israel em que aparentemente não se dedicou à representação teatral e sim a escrever e proferir palestras sobre o KZ Theater, não mais existente.

Buscarei estabelecer diálogos entre o teatro de Feder e referenciais teóricos de outros autores também dedicados ao tema do teatro durante o Holocausto, como Michael Balfour, Sophie Fetthauer, Elinor Fuchs, Alvin Goldfarb Schumacher, John London, Rebecca Rovit e Claude E. Stephen Wilmer. Autores que falam sobre Holocausto e anti-semitismo como Theodor Adorno, Zygmunt Bauman, Walter Benjamin, Elias Canetti, Viktor E. Frankl, Erving Goffman, Israel Gutman, Max Horkheimer, Primo Levy, e Stephen Wilner poderão enriquecer este diálogo.

Neste percurso, acredito ser possível estabelecer paralelos entre a Companhia KZ Theater criada e dirigida por Sami Feder na década de 1940 e o Théâtre du Soleil, 
companhia contemporânea francesa, sob a coordenação de Ariane Mnouchkine, até mesmo porque ambos se inspiraram no teatro político de Bertolt Brecht.

\section{REFERÊNCIAS BIBLIOGRÁFICAS}

Arquivo Pessoal da Profa. Dra. Zlata Zaretsky, Jerusalém, Israel.

BALFOUR, Michael (org.). Theater and War, 1933-1945: performance in extremis. USA: Berghahn Books, 2001.

BAUMAN, Zygmunt. O mal-estar da pós-modernidade. Rio de Janeiro: Jorge Zahar, 1998.

BOROWSKI, Mateusz; MALGORZATA Sugiera. Fictional Realities/Real Fictions. London: Cambridge Scholars Publishing, 2007.

BRENNER, Michael. After the Holocaust: rebuilding Jewish Lives in postwar Germany/translated by Barbara Harshav. New Jersey: Princeton,1997.

CARNEIRO, Maria Luiza Tucci. Holocausto, crime contra a humanidade. São Paulo: Ática, 1998. (Coleção História em Movimento.)

FEDER, Sami. Anotações para o diário ídiche do Teatro do Campo de Concentração em Bergen Belsen, 1945/1947, de Sami Feder, diretor artístico e regente. (YVA 0.70/30 file that relates to Farseykhenish fun Sami Feder or fun Tagebuch)

FETTHAUER, Sophie. Musik und Theater im DP-Camp Bergen - Belsen Zum Kulturleben der jüdischen Displaced Persons 1945-1950.Musik im Dritten Reich und im Exil - Band 16., Hamburgo: Von Buchel Vernag, 2010.

FRANKL, Viktor. Em Busca de Sentido. Rio de Janeiro: Editora Vozes, 2010

FUCHS, Elinor (org.). Plays of the holocaust - an international antology. Nova Iorque:, Theatre Communications Group, 1997.

GHETTO. Andrius Juzenas. Lituânia: 2006. Filme com roteiro de Joshua Sobol.

GOFFMAN, Erving. Estigma. São Paulo, LTC, 1988.

GUTMAN, Israel. Holocausto y memoria. Jerusalém: Centro Zalman Shazar de História Judia \& Yad Vashem, 2003.

HOC - Holocaust On Line in Virtual Archive All About Jewish Theater. Electronic adress: http:/www.jewish-theater.com

KORCZAK, Janusz. Diário do Gueto. Tradução de Jorge Rochtlitz. São Paulo: Perspectiva, 1986.

LONDON, John. Theatre under the Nazis. Manchester: Manchester University Press, 2000.

MUSEU DO HOLOCAUSTO DE WASHINGTON. Acervo bibliográfico, sonoro e visual.

MUSEU DO HOLOCAUSTO PARA CRIANÇAS. Kibutz Lohamei Haguetaot, Acco, Israel. Acervo bibliográfico, sonoro e visual.

MUSEU YAD VASHEM. Jerusalém, Israel. Acervo bibliográfico, sonoro e visual.

PASCAUD, Fabienne. A Arte do Presente: Ariane Mnouchkine. Rio de Janeiro: Cobogó, 2011.

PLUNKA, A. Gene. Staging Holocaust Resistance.New York: PALGRAVE Macmillan, 2012.

ROVIT, Rebecca. Cultural Ghettoization and Theater during the Holocaust: Performance as a Link to Community. Holocaust Genocide Studies, Oxford, 19 (3), p. 459-486, inverno de 2005.

ROVIT, Rebecca; GOLDFARB, Alvin. Theatrical performance during the holocaust. Baltimore:The Johns Hopkins University Press, 1999. 
SELIGMANN-SILVA, Márcio. O local da diferença: ensaios sobre memória, arte, literatura e tradução. São Paulo: Editora 34, 2005.

SKLOOT, Robert (org.). The Theatre of the Holocaust. Volumes 1 e 2. Lexington: The University of Wisconsin Press, 2011.

SOBOL, Joshua. Ghetto, in FUCKS, Elinor (org.). Plays of the holocaust - an international antology. Nova Iorque:, Theatre Communications Group, 1997.

WILMER, Stephen E. Nationalism in recent german theatre: post-traumatic drama or postdramatic trauma. In Mateusz Borowski e Malgorzata Sugiera. Fictional realities/real fictions, Newcastle: Cambridge Scholars Publishing, 2007.

ZARETSKY, Zlata. The story of Sami Feder - producer for the "Kazet" theater. All about Jewish Theatre. News. Disiponível em: [http://www.jewishtheatre.com/visitor/article_display.aspx?refpage $=\mathrm{http} \% 3 \mathrm{a} \% 2 \mathrm{f} \% 2 \mathrm{fwww}$.jewishtheatre.com $\% 2$ fvisitor $\% 2$ fsearch.aspx $\% 3$ searchterm $\% 3 \mathrm{dFeder} \% 26$ authorid $\% 3 \mathrm{~d} 1765 \&$ articleID=3533\&pageNumber=1]. Acesso em: 09/01/2012.

ZARETSKY, Zlata. The Phenomenon of theater Israeli, A view of history and the present time. Jerusalem: Zaar Publishers, 1997. 